\title{
Vibrations of the Amino Group in Glycine Hydrochloride: Spectral Hole Burning and Isotope Shifts
}

\author{
Hung-Wen Li, Gu-Sheng Yu, ${ }^{\dagger}$ and Herbert L. Strauss* \\ Department of Chemistry, University of California, Berkeley, California 94720-1460 \\ Received: August 6, 1997; In Final Form: October 27, $1997^{\otimes}$
}

\begin{abstract}
Hole burning of the N-D stretches of the deuterium-doped glycine hydrochloride results in holes and antiholes in the various regions of the spectrum. These can be assigned to various orientations of the $\mathrm{NH}_{2} \mathrm{D}^{+}$moiety. Bands at about $800 \mathrm{~cm}^{-1}$ are probably the amino group rocks, but the other changing bands must arise from complex mixtures of the valence vibrations. The hole burning takes considerable time, on the order of $1 \mathrm{~h}$, and puts most of the $\mathrm{NH}_{2} \mathrm{D}^{+}$in the orientation of lowest energy.
\end{abstract}

\section{Introduction}

We have recently shown that we can hole-burn a number of amino acid salts. ${ }^{1}$ The salts are doped with deuterium to form some $\mathrm{NH}_{2} \mathrm{D}^{+}$. Irradiation of the $\mathrm{N}-\mathrm{D}$ stretching bands then results in rotation of the $\mathrm{NH}_{2} \mathrm{D}^{+}$moiety and forms a number of spectral holes and antiholes. So far, only glycine and alanine hydrochlorides in the $\mathrm{N}-\mathrm{D}$ stretching region have been investigated. We note, however, that the hole burning seems to be widely applicable, and we have been able to hole-burn a number of other amino acid salts ${ }^{2}$ as well as many ammonium salts. ${ }^{3,4}$

In view of the importance of amino acids as the building blocks of proteins and the widespread use of vibrational spectroscopy for analysis, we have considered the simplest amino acid salt, glycine hydrochloride, in more detail. The vibrations and spectra of the simple amino acids and their salts were analyzed as much as possible in the 1950s using the methods then available. Hole burning is a new technique to use in trying to resolve longstanding problems. The hole burning rotates the $\mathrm{NH}_{2} \mathrm{D}^{+}$group and thus changes the configuration of the amino acid molecule. This changes all the vibrational bands that are sensitive to the $\mathrm{NH}_{2} \mathrm{D}^{+}$orientation, and so it is not surprising that we are able to find holes and antiholes at the positions of the amino deformation and rocking bands as well as at the position of the $\mathrm{N}-\mathrm{D}$ stretches. In addition, we are able to repeat the hole-burning experiments with $N^{15}$-glycine, and this further characterizes the infrared bands.

The vibrational spectra of glycine hydrochloride and its isotopomers below $2000 \mathrm{~cm}^{-1}$ have been systematically investigated and assigned by Tsuboi et al. ${ }^{5}$ More recently, a number of studies have considered the region above $2500 \mathrm{~cm}^{-1}$ as well. $^{6-8}$ A continuing problem is the existence of numerous multiple bands due to combinations and Fermi resonances in both the amino acids and their salts. $1,6,8,9,10$

The crystal structure of glycine hydrochloride has been studied by both X-ray and neutron diffraction, ${ }^{11}$ and we list the neutron structural parameters for the hydrogen bonds in Table

$\dagger$ Present address: Industrial Technology Research Institute-Center for Measurement Standards, 321 Kuang Fu Road, Section 2, Hsinchu, Taiwan 30042 .

${ }^{\otimes}$ Abstract published in Advance ACS Abstracts, December 15, 1997.
1. There are four hydrogen bonds, three for the $\mathrm{NH}_{3}{ }^{+}$and one for the $\mathrm{OH}$ group. Of the $\mathrm{N}-\mathrm{H}$ hydrogen bonds, the one labeled " 3 " is bifurcated and very weak.

\section{Experimental Section}

The samples were prepared, as previously described, ${ }^{1}$ by dissolving the glycine in slightly warm concentrated $\mathrm{HCl}$ containing a bit of $\mathrm{D}_{2} \mathrm{O}$. The $N^{14}$-glycine and the $\mathrm{N}^{15}$ compound (98\% $N^{15}$-glycine) were from Aldrich (Chemical Abstracts numbers 56-40-6 and 7299-33-4, respectively).

Spectra were taken with different amounts of deuterium to make sure that only bands due to glycine- $\mathrm{HCl}$ molecules containing at most one deuterium atom were observed. The apparatus was also the same as previously described, and the spectra were taken with the MCT/B detector to cover the midinfrared. ${ }^{1,4}$ The gain on the MCT was sometimes set high in an attempt to see the weaker bands. If the overall signal was too large, the detector was driven nonlinear, yielding excess noise in the difference spectra at the position of the stronger bands. This accounts for some of the characteristics of the observed spectra noted below.

The laser irradiation time was $0.5-1 \mathrm{~h}$. We found that letting the broad-band infrared source (the Nernst glower, which is the spectrometer source) irradiate the sample overnight led to holes and antiholes much like those produced by the laser irradiation. To determine whether any of the infrared bands we observe could be due to the other salt of glycine and hydrochloric acid, we made diglycine hydrochloride, (glycine) ${ }_{2} \mathrm{HCl}$, doped it with some deuterium, and took the spectrum. The diglycine hydrochloride can be made straightforwardly by simply dissolving 2 equiv of glycine into 1 equiv of $\mathrm{HCl}^{1}{ }^{12}$

The light path between the laser and sample is not completely purged of $\mathrm{CO}_{2}$. This has made hole burning in the region of the atmospheric absorption $\left(\approx 2390-2290 \mathrm{~cm}^{-1}\right)$ problematic, since the laser power at the sample is low and very dependent on the exact frequency. Another problem arises in comparing the spectra of two isotopomers. Since the sample has to be changed for each isotopomer, the baseline invariably changes as well. This adds uncertainty to the subtractions. The subtractions were done by adjusting the baseline on each spectrum separately, scaling to match the two spectra as well as possible, and then subtracting. 
TABLE 1: Hydrogen-Bonding Geometry and Deuterium Stretching Frequencies of Glycine Hydrochloride

\begin{tabular}{|c|c|c|c|c|c|c|c|}
\hline \multirow[b]{2}{*}{ position } & \multicolumn{3}{|c|}{ neutron diffraction ${ }^{a}$} & \multirow[b]{2}{*}{$\angle \mathrm{N}-\mathrm{H} \cdots \mathrm{B}(\mathrm{deg})$} & \multirow[b]{2}{*}{$\mathrm{N}^{14}-\mathrm{D} \operatorname{stretch}^{b}\left(\mathrm{~cm}^{-1}\right)$} & \multirow[b]{2}{*}{$\mathrm{N}^{15}-\mathrm{D}$ stretch ${ }^{b}\left(\mathrm{~cm}^{-1}\right)$} & \multirow[b]{2}{*}{$\Delta\left(\mathrm{cm}^{-1}\right)$} \\
\hline & $\mathrm{N}-\mathrm{H} \cdots \mathrm{B}$ & $\mathrm{H} \cdots \mathrm{B}(\AA)$ & $\mathrm{N} \cdots \mathrm{B}(\AA)$ & & & & \\
\hline 1 & $\mathrm{~N}-\mathrm{H}^{1} \cdots \mathrm{Cl}$ & $2.160(2)$ & $3.189(1)$ & $170.8(1)$ & 2238 & 2230 & 8 \\
\hline 2 & $\mathrm{~N}-\mathrm{H}^{2} \cdots \mathrm{Cl}$ & $2.123(2)$ & $3.140(1)$ & $166.4(2)$ & 2187 & 2178 & 9 \\
\hline \multirow[t]{3}{*}{$3^{c}$} & $\int \mathrm{N}-\mathrm{H}^{3} \cdots \mathrm{Cl}$ & $2.593(2)$ & $3.300(1)$ & $126.7(2)$ & 2368 & 2359 & 9 \\
\hline & $\left\{\mathrm{N}-\mathrm{H}^{3} \cdots \mathrm{O}\right.$ & $2.222(2)$ & $2.992(1)$ & $131.6(2)$ & & & \\
\hline & $\mathrm{O}-\mathrm{H} \cdots \mathrm{Cl}$ & $2.008(2)$ & $3.004(1)$ & $178.5(2)$ & 2190 & 2190 & 0 \\
\hline
\end{tabular}

${ }^{a}$ Reference 11; the numbers in parentheses are the uncertainties given in this reference. ${ }^{b}$ This work and ref $1 .{ }^{c}$ Bifurcated hydrogen bond.

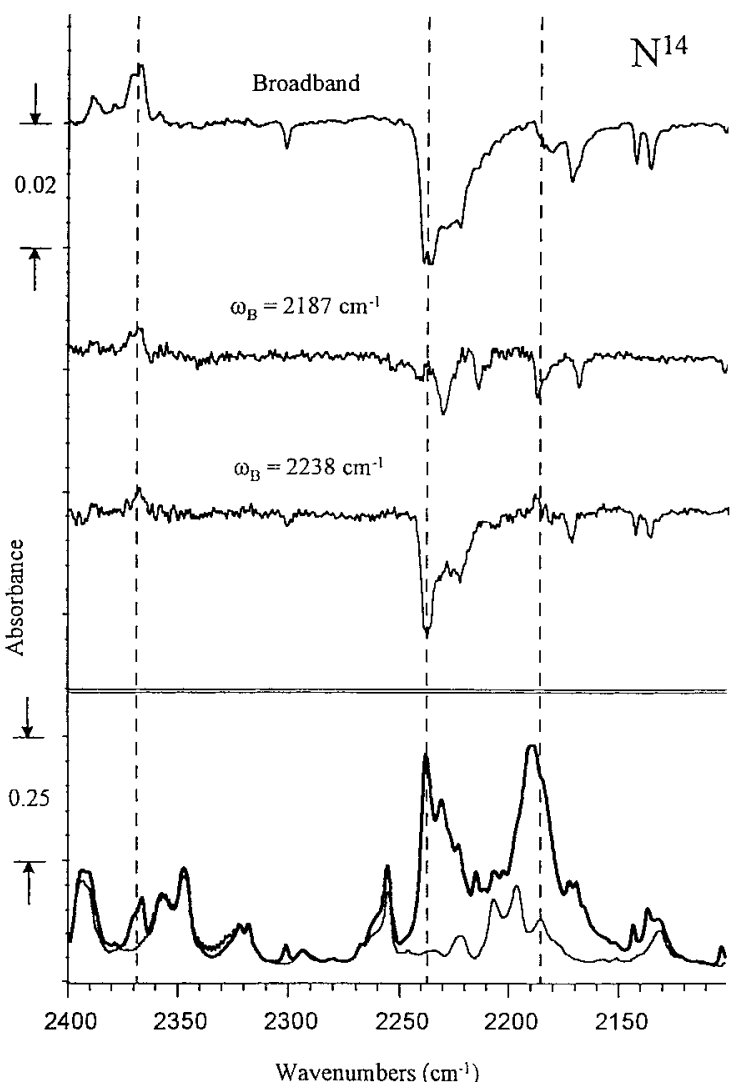

Figure 1. Infrared spectral hole burning of $N^{14}$-glycine hydrochloride doped with about $4 \%$ deuterium. The spectra show the region of the $\mathrm{N}-\mathrm{D}$ and $\mathrm{O}-\mathrm{D}$ stretching bands and were taken at $7 \mathrm{~K}$. The absorption spectra of the deuterated glycine hydrochloride (heavy line) and the undeuterated species (light line) are shown in the bottom panel. The bands arising from the deuterium are those that appear in the difference between these two spectra. The fiducial lines are at 2368, 2238, and $2187 \mathrm{~cm}^{-1}$. The upper panels show the results of irradiation of the deuterated sample with the broad-band source and with the laser set to 2187 and $2238 \mathrm{~cm}^{-1}$, respectively. The spectra are the differences between those taken before irradiation and those taken after. Holes appear at 2238 and $2187 \mathrm{~cm}^{-1}$ with a small antihole at $2368 \mathrm{~cm}^{-1}$. The laser irradiation time was $0.5-1 \mathrm{~h}$. The irradiation time for broadband irradiation was about $11 \mathrm{~h}$. Note the change in the vertical scale between the absorption spectra and the difference spectra.

\section{Results}

The $\mathrm{N}-\mathrm{D}$ stretching region of the $N^{14}$-glycine hydrochlorides and of the $\mathrm{N}^{15}$ compounds are shown in Figures1 and 2, respectively. The bottom panel of each figure shows the spectrum of the hydrogen compound and that of the slightly deuterated one. The difference between these (not shown in the figures) reveals the bands that involve deuterium. The many bands seen in the spectra arise from the $\mathrm{N}-\mathrm{D}$ and the $\mathrm{O}-\mathrm{D}$ stretches with additional bands from combinations and vibrational resonances.

The main features of the $\mathrm{N}^{14}$ and $\mathrm{N}^{15}$ compounds are very similar, as expected. The $\mathrm{N}-\mathrm{D}$ stretches are identified by hole

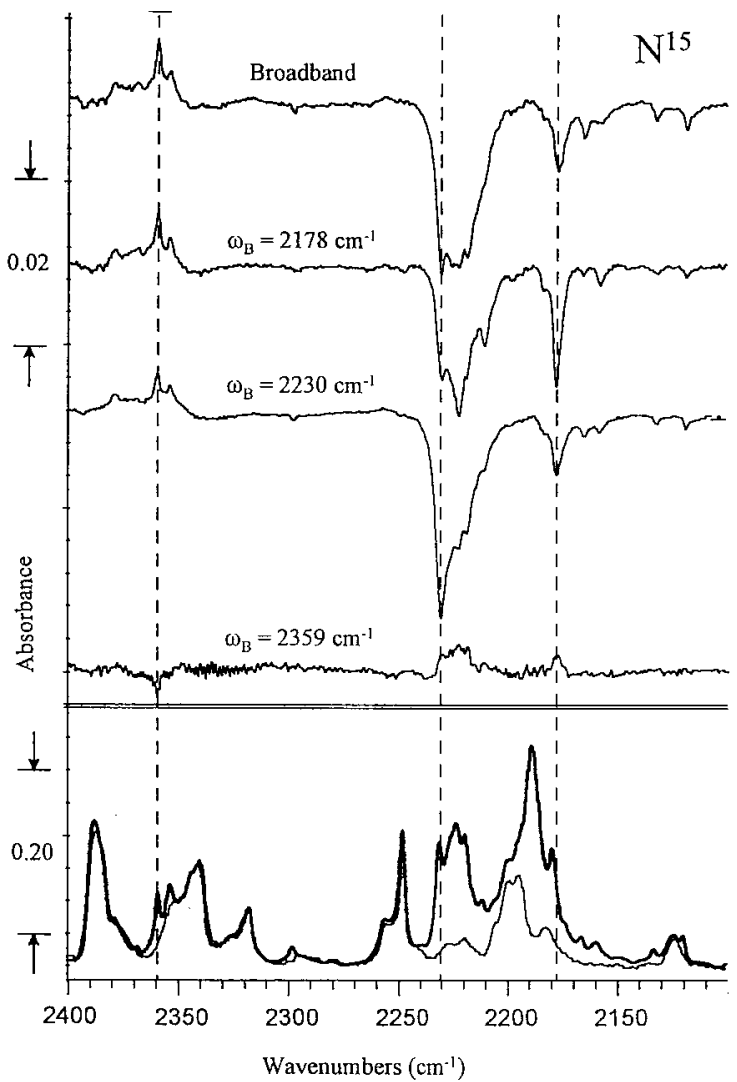

Figure 2. The spectra of $N^{15}$-glycine hydrochloride. See the caption of Figure 1. The fiducial lines are at 2359,2230 , and $2178 \mathrm{~cm}^{-1}$. There are four hole-burning spectra shown: three are analogous to those in Figure 1. In addition, irradiation at the highest wavenumber $\left(2359 \mathrm{~cm}^{-1}\right)$ produces small antiholes.

burning and the resulting spectra are shown in the top panels. The N-D stretching bands are difficult to identify from the absorption spectra because of all the "extra" bands, but the bands that can be burned are $\mathrm{N}-\mathrm{D}$ stretching bands. For the $\mathrm{N}^{14}$ compound, the burned bands are at 2187 and $2238 \mathrm{~cm}^{-1}$ (Figure 1). The third $\mathrm{N}-\mathrm{D}$ band is at $2368 \mathrm{~cm}^{-1}$ and is identified by the presence of an antihole at this position (irradiating at 2368 $\mathrm{cm}^{-1}$ did not produce a detectable hole, probably because of the absorption of carbon dioxide in the optical path of the laser). The $\mathrm{N}^{15}$ compound shows clear holes on irradiating at 2178 , 2230, and $2359 \mathrm{~cm}^{-1}$ (Figure 2). The $\mathrm{N}^{15}-\mathrm{N}^{14}$ shift is about $9 \mathrm{~cm}^{-1}$, which is the magnitude expected. Note that both compounds have complicated absorptions and holes at wavenumbers just below the position of the middle $\mathrm{N}-\mathrm{D}$ stretch. At equilibrium, one might expect the $\mathrm{NH}_{2} \mathrm{D}^{+}$moiety to be in the position with the $\mathrm{D}$ forming the weakest, highest-frequency hydrogen bond, since this is the conformation that yields the lowest zero-point energy. The antiholes at 2368 and $2359 \mathrm{~cm}^{-1}$ indicate that this is indeed the conformation produced. We note, however, that the conformations produced by hole burning represent the steady state rather than equilibrium. 


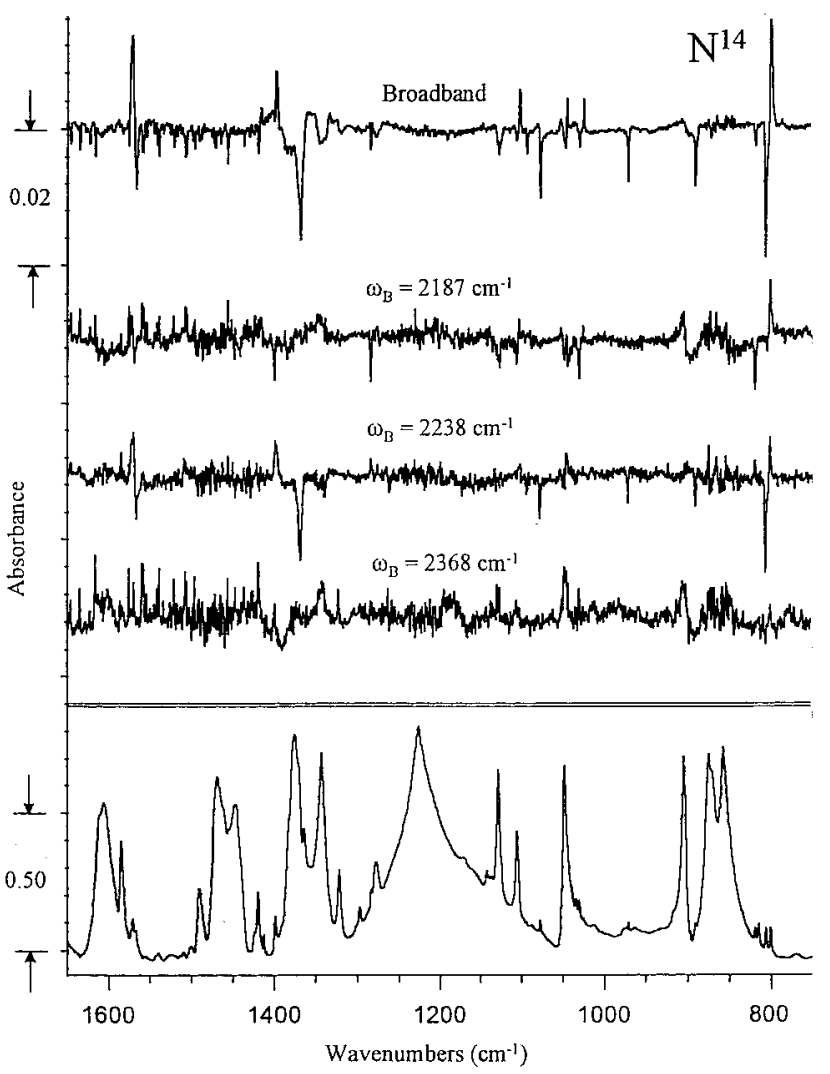

Figure 3. The mid-infrared region of the spectrum of deuterium-doped $N^{14}$-glycine hydrochloride. The results of hole burning at the three discrete $\mathrm{N}-\mathrm{D}$ stretching positions as well as that produced by broadband irradiation are shown.

The figures also show the results of long (overnight) broadband infrared irradiation. The results of such irradiation depend on the absorption of the excitation in different regions of the spectrum, the various quantum efficiencies of the hole burning, and the dark transformation rates.

Most likely the broad-band irradiation effects hole burning in the region of the N-D stretches and perhaps at higher frequencies. The active spectral region could be determined experimentally by using infrared cutoff filters, but we did not do this. The similarity among results of the broad-band irradiation and those at discrete frequencies indicates that the irradiation times are all long compared to the dark rates, that is, the hole-burning spectra are close to the steady-state situation.

There is a prominent band at about $2190 \mathrm{~cm}^{-1}$, which is close to bands that do burn, but does not burn itself. Curving fitting the bands for both the $\mathrm{N}^{14}$ and $\mathrm{N}^{15}$ spectra gives a peak at 2190 $\mathrm{cm}^{-1}$ in the $\mathrm{N}^{14}$ spectrum and $2189 \mathrm{~cm}^{-1}$ in the $\mathrm{N}^{15}$ spectrum. These are accompanied by two smaller peaks at 2187 and 2183 $\mathrm{cm}^{-1}\left(\mathrm{~N}^{14}\right)$ and 2184 and $2178 \mathrm{~cm}^{-1}\left(\mathrm{~N}^{15}\right)$. We assign the largest peak to the $\mathrm{O}-\mathrm{D}$ stretch and the two others to the lowest frequency $\mathrm{N}-\mathrm{D}$ stretch, which has been split, probably by a Fermi resonance.

Irradiating one of the $\mathrm{N}-\mathrm{D}$ stretches rotates the $\mathrm{NH}_{2} \mathrm{D}^{+}$group to a new position, and the various deformations which involve the deuterium atom should change as well. Once again, we identify the bands by looking for the holes and antiholes. The mid-infrared spectrum for $\mathrm{N}^{14}$ is shown in Figure 3 and that for $\mathrm{N}^{15}$ is in Figure 4. The upper panels show the holes and antiholes produced by irradiation of the N-D stretches. Figures 5,6 , and 7 show expanded regions of these spectra. The holes and antiholes show up at about 780-840 $\mathrm{cm}^{-1}$ (Figure 5), 950 to $1120 \mathrm{~cm}^{-1}$ (Figure 6), and $1270-1410 \mathrm{~cm}^{-1}$ (Figure 7). The

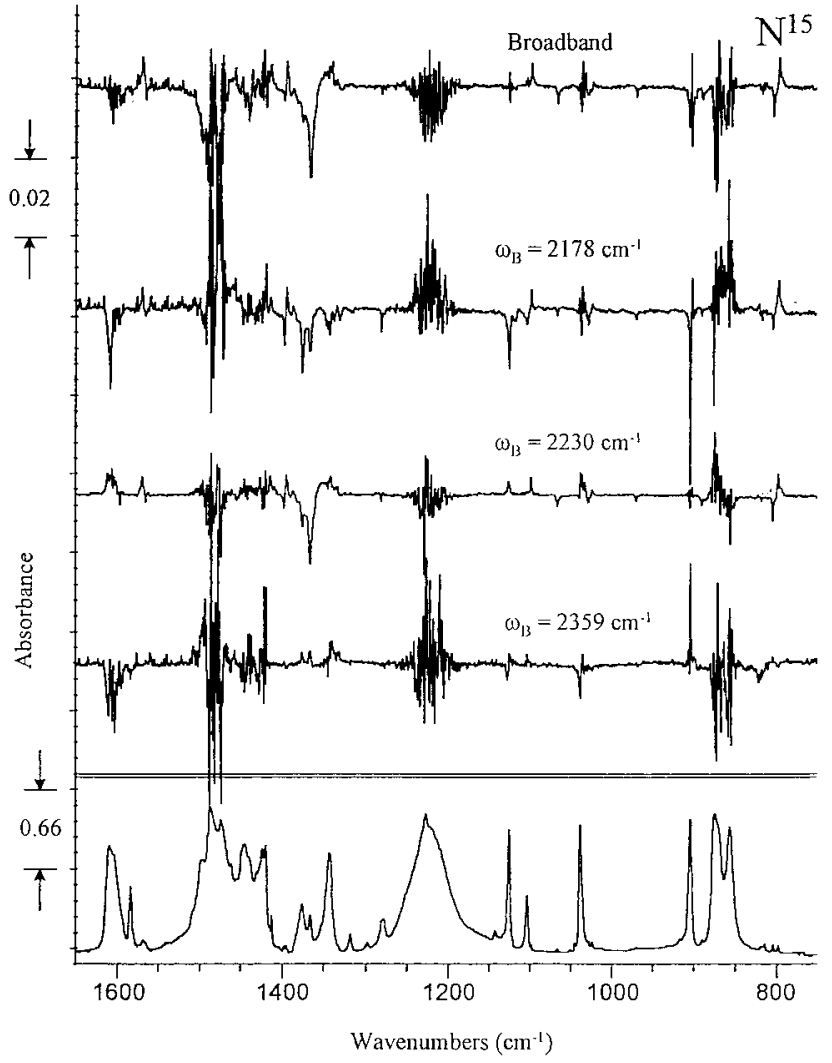

Figure 4. The mid-infrared region of the spectrum of the deuteriumdoped $\mathrm{N}^{15}$ compound. The noise in the difference spectra at the positions of the stronger absorption bands is due to the nonlinearity in the detector (see text).

various sections of Figures 5, 6, and 7 (i.e., the $\mathrm{N}^{14}$ and the $\mathrm{N}^{15}$ parts) are each to a different scale. In each case, the baseline has been adjusted to appear as flat as possible. Figures 3 and 4 show the peaks on one uniform scale, of course.

Most of the spectra that have been assigned previously are for the all-hydrogen glycine and its salts for both $\mathrm{N}^{14}$ and $\mathrm{N}^{15}$ and the compounds with all the amino hydrogens substituted by deuterium for both $\mathrm{N}^{14}$ and $\mathrm{N}^{15} \cdot 5,7-10$ In addition, some spectra have been recorded of glycine and its salts with the methylene group deuterated. This would normally be quite enough information to assign all the fundamental bands, but there are a number of indications that things are not so simple. For example, the $\mathrm{N}^{15}$ shift for some of the $\mathrm{NH}_{3}{ }^{+}$deformations of both glycine and alanine have been reported as positive. ${ }^{9}$ Since the shifts must be negative, ${ }^{13}$ the bands must be misassigned, shifted by a Fermi resonance or subject to other complications.

Our spectra are, of course, for $\mathrm{NH}_{2} \mathrm{D}^{+}$and this requires interpolation between the spectra of $\mathrm{NH}_{3}{ }^{+}$and those of $\mathrm{ND}_{3}{ }^{+}$. The $\mathrm{NH}_{3}{ }^{+}$and $\mathrm{ND}_{3}{ }^{+}$stretches span representations $\mathrm{A}$ and $\mathrm{E}$ in $C_{3 v}$. These will split into $\mathrm{A}^{\prime}$ and $\mathrm{A}^{\prime}+\mathrm{A}^{\prime \prime}$ in $C_{s}$ and of course will be modified by the hydrogen bonding in the crystals, but the $\mathrm{N}-\mathrm{D}$ stretch of the $\mathrm{NH}_{2} \mathrm{D}^{+}$should retain its unique character. Since the $\mathrm{D}$ can be in any one of three positions and the site symmetry is $C_{1}$, each $\mathrm{N}-\mathrm{D}$ stretch can be made up of a set of three bands. This set of three N-D stretches is identified in Figures 1 and 2 and Table 1.

The bending modes of the $\mathrm{NH}_{3}{ }^{+}$(or $\mathrm{ND}_{3}{ }^{+}$) are a symmetric deformation $\left(\mathrm{A}_{1}\right)$ and a degenerate deformation $(\mathrm{E})$, together with the rock (E). ${ }^{14}$ The last normal mode of the $\mathrm{NH}_{3}{ }^{+}$group is the torsion $\left(\mathrm{A}_{2}\right)$, which will not concern us further here. The $\mathrm{E}$ modes will break up into $\mathrm{A}^{\prime}$ and $\mathrm{A}^{\prime \prime}$ components in $C_{s}$ and 


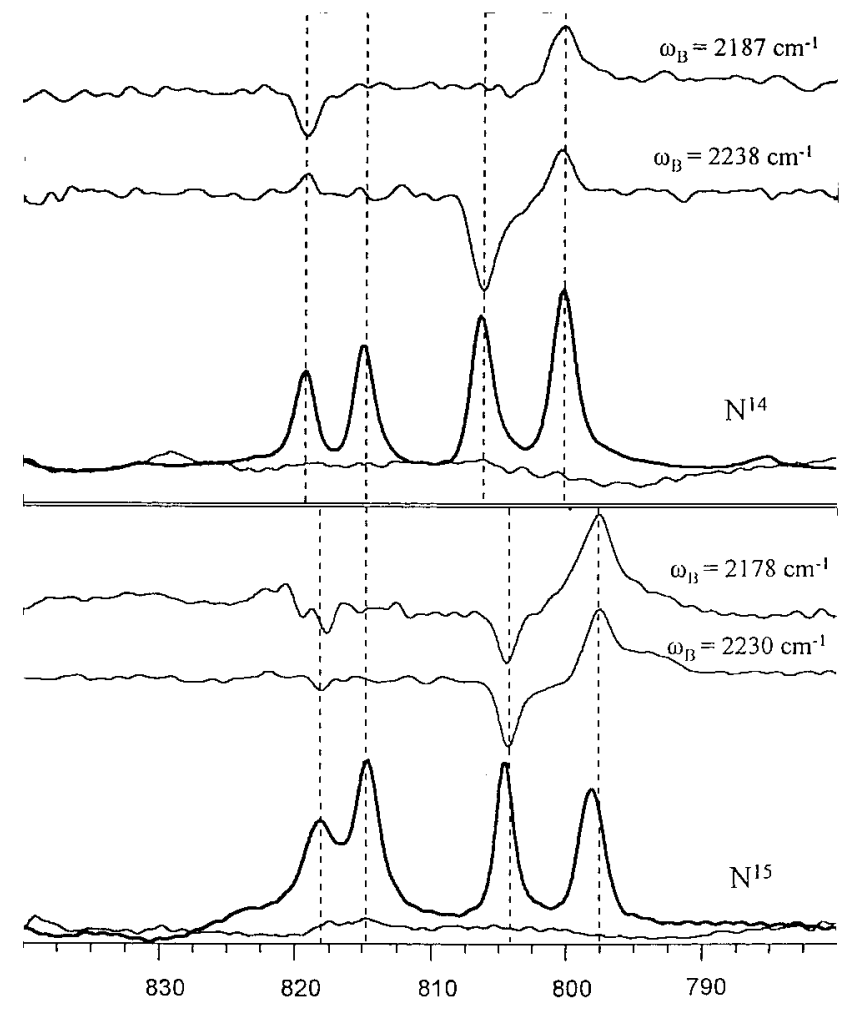

Wavenumbers $\left(\mathrm{cm}^{-1}\right)$

Figure 5. The same spectra as in Figures 3 and 4 on an expanded scale to show only the region from 780 to $840 \mathrm{~cm}^{-1}$. The upper and lower sections of the figure are for the $\mathrm{N}^{14}$ and $\mathrm{N}^{15}$ compounds. The heavy curves in the absorption spectra are for the deuterium-doped species, and the light curves are for the undoped species. As in the other figures, the vertical scales on the hole-burning spectra are much more expanded than in the absorption spectra. They are not the same for the two isotopes. The position of the holes mostly matches the position of small absorption features. The fiducial lines are at 819.2, 814.7, 806.1, and $800.1 \mathrm{~cm}^{-1}$ (top) and 818.1, 814.7, 804.3, and 797.5 $\mathrm{cm}^{-1}$ (bottom). The peak at 814.7 does not shift with the change in the nitrogen isotope.

of course into $\mathrm{A}+\mathrm{A}$ in $C_{1}$. We expect that the $\mathrm{N}-\mathrm{D}$ bend character will be mostly in one deformation and one rock, and again each of these can be different in each of the three different $\mathrm{N}-\mathrm{D}$ positions.

We start with the $800 \mathrm{~cm}^{-1}$ region. The spectra with deuterium show four clear isolated bands (Figure 5), and these include the $\mathrm{NH}_{2} \mathrm{D}^{+}$rocks. Three of these show small isotope shifts on changing from $\mathrm{N}^{14}$ to $\mathrm{N}^{15}$ (Figure 5). We see holes and antiholes on burning at the lower two of the three $\mathrm{N}-\mathrm{D}$ stretching bands for both nitrogen isotopes. The third N-D stretch is too weak to use for producing holes in other regions of the spectrum, yielding only a small hole in the stretching region of the spectrum for $\mathrm{N}^{15}$ (Figure 2) and none at all for $\mathrm{N}^{14}$. Burning at the two stretches yields holes and antiholes at 800,806 , and $819 \mathrm{~cm}^{-1}\left(\mathrm{~N}^{14}\right)$ and 797.5, 804, and $818 \mathrm{~cm}^{-1}$ $\left(\mathrm{N}^{15}\right)$. The remaining band, $815 \mathrm{~cm}^{-1}$, for both the $\mathrm{N}^{14}$ and $\mathrm{N}^{15}$ compounds does not shift on $\mathrm{N}$ substitution and does not change on irradiation and so is not a rock. This band either is the $\mathrm{C}-\mathrm{C}$ stretch or belongs to a mode that mixes valence vibrations. Another possibility is that the band arises from a change in quantum number for a combination of other normal modes. Another obvious candidate is one of the $\mathrm{C}-\mathrm{O}-\mathrm{D}$ bends, but these have been assigned in many amino acids at about $1050 \mathrm{~cm}^{-1}$ for the in-plane motion and about $600 \mathrm{~cm}^{-1}$ for the out-of-plane motion. ${ }^{9}$

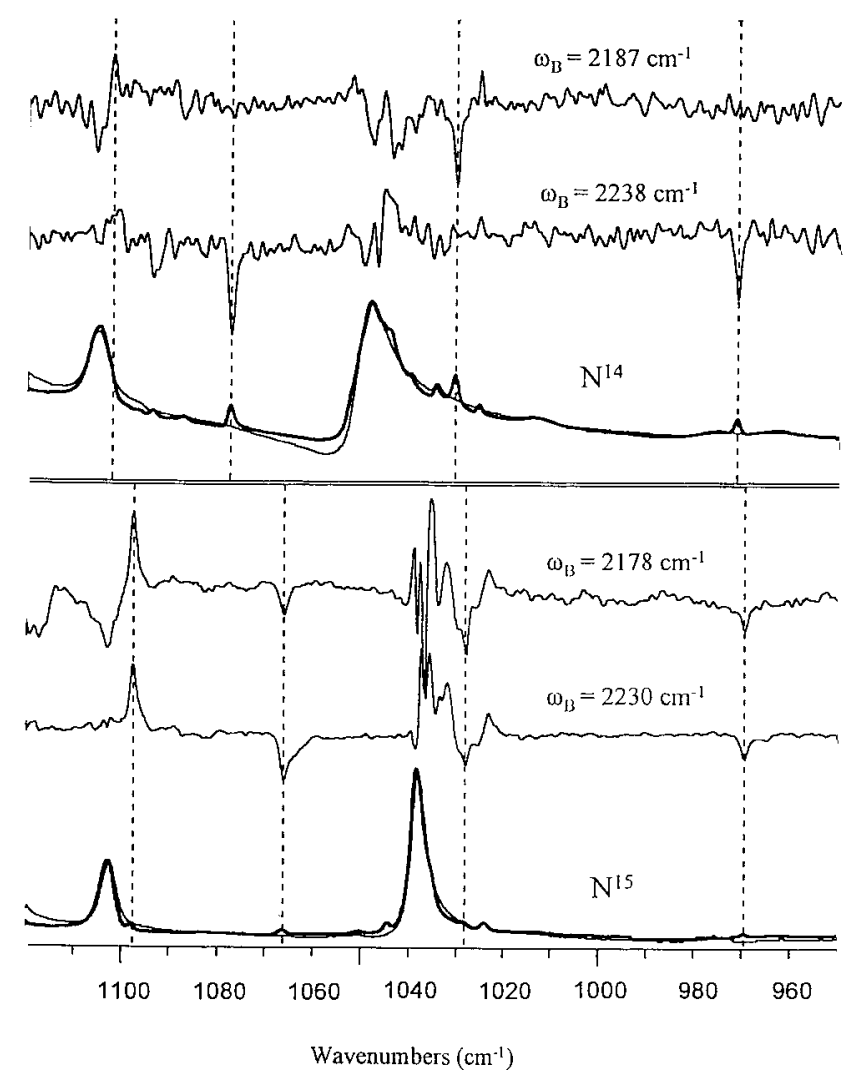

Figure 6. Similar to Figure 5 for the region 950 to $1120 \mathrm{~cm}^{-1}$. The fiducial lines are at 1102.4, 1077.8, 1030.8, and $971.5 \mathrm{~cm}^{-1}$ (top) and 1097.8, 1066.1, 1028.3 and $969.4 \mathrm{~cm}^{-1}$ (bottom).

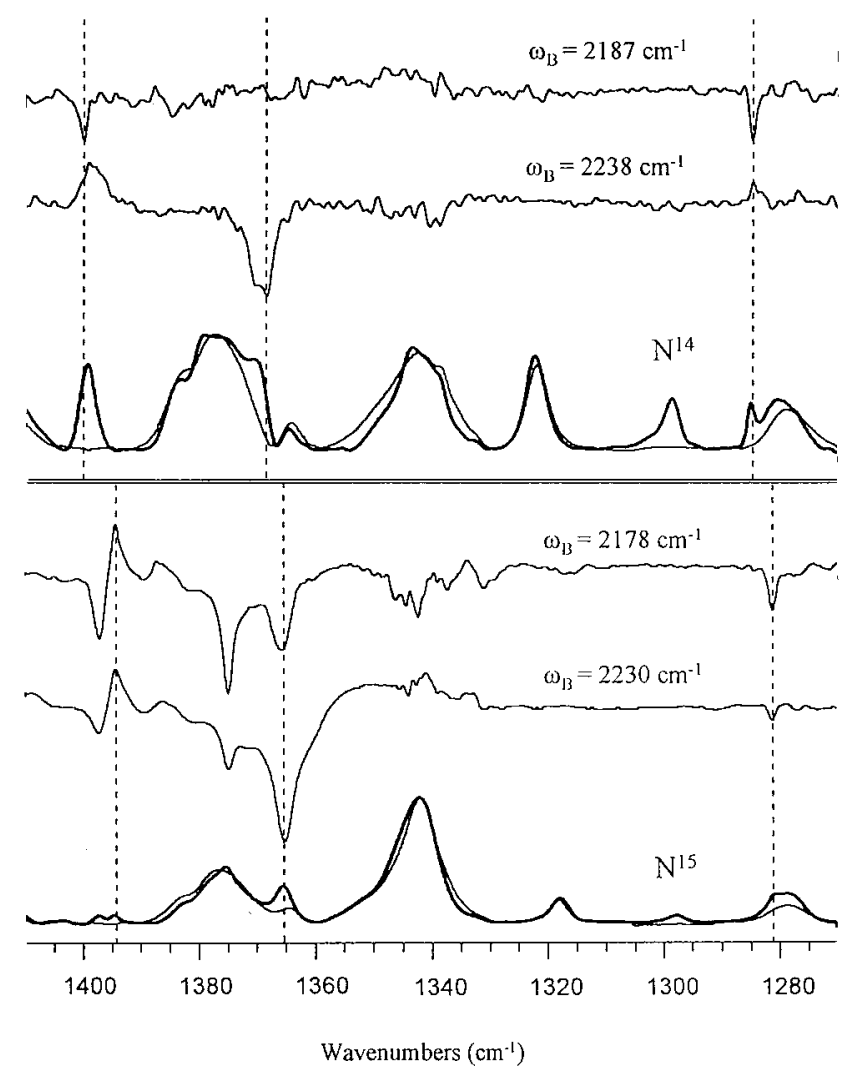

Figure 7. Similar to Figure 5 for the region 1270 to $1410 \mathrm{~cm}^{-1}$. Note that at about $1395 \mathrm{~cm}^{-1}$ there are two small absorption bands, and both a hole and an antihole are produced by irradiation of the $\mathrm{N}^{15}$ compound. The fiducial lines are at $1398.9,1368.5$ and $1284.8 \mathrm{~cm}^{-1}$ (top) and 1394.5, 1365.5, and $1281.5 \mathrm{~cm}^{-1}$ (bottom). 
TABLE 2: Mid-Infrared Modes of Partially Deuterated Glycine Hydrochloride

\begin{tabular}{|c|c|c|c|c|}
\hline $\begin{array}{c}\mathrm{N}^{14} \\
\left(\mathrm{~cm}^{-1}\right)\end{array}$ & $\begin{array}{c}\mathrm{N}^{15} \\
\left(\mathrm{~cm}^{-1}\right)\end{array}$ & $\begin{array}{l}\text { difference } \\
\left(\mathrm{cm}^{-1}\right)\end{array}$ & $\begin{array}{l}\text { hole-burning } \\
\text { pattern }^{a}\end{array}$ & $\begin{array}{c}\mathrm{NH}_{2} \mathrm{D}^{+} \\
\text {orientation }\end{array}$ \\
\hline 800 & 797.5 & 2.5 & $\uparrow \uparrow(\uparrow \uparrow)$ & 3 \\
\hline 806 & 804 & 2 & $-\downarrow(\downarrow \downarrow)$ & 1 \\
\hline 819 & 818 & 1 & $\downarrow \uparrow(\downarrow \downarrow)$ & 2 \\
\hline 815 & 815 & 0 & not burnable & \\
\hline 972 & 969 & 3 & $-\downarrow(\downarrow)$ & 1,2 \\
\hline 1031 & 1028 & 3 & $\downarrow-(\downarrow \downarrow)$ & 1,2 \\
\hline 1078 & 1066 & $12(?)^{b}$ & $-\downarrow(\downarrow)$ & $1,2(?)^{b}$ \\
\hline 1102 & 1098 & 4 & $\downarrow-(\uparrow \uparrow)$ & 3 \\
\hline 1285 & 1282 & 3 & $\downarrow \uparrow(\downarrow \downarrow)$ & 1,2 \\
\hline 1369 & 1366 & 3 & $-\downarrow(\downarrow)$ & 1,2 \\
\hline$?$ & 1375 & $?^{c}$ & $(\downarrow)$ & $c$ \\
\hline $1399^{d}$ & $1395^{d}$ & 4 & $\downarrow \uparrow(\uparrow \uparrow)$ & 3 \\
\hline
\end{tabular}

${ }^{a}$ Indication of the holes $(\downarrow)$ and antiholes ( $\left.\uparrow\right)$. See the figures. The first two arrows indicate the holes and antiholes on burning with the two irradiations for the $\mathrm{N}^{14}$ compound at 2187 and $2238 \mathrm{~cm}^{-1}$ and the next two for the $\mathrm{N}^{15}$ isotopomer at 2178 and $2230 \mathrm{~cm}^{-1}$. The hole burning at each pair of stretching frequencies corresponds to bands that overlap, and this makes it difficult to distinguish which other bands belong to orientations 1 and $2 .{ }^{b}$ The isotope shift of $12 \mathrm{~cm}^{-1}$ is large and suggests the two bands (and holes) may not be related. ${ }^{c}$ There is no obvious $\mathrm{N}^{14}$ partner to this band and hole. ${ }^{d}$ There are two bands near this wavenumber.

The pattern of holes and antiholes is not what might have been expected. Irradiating at $2187\left(\mathrm{~N}^{14}\right)$ yields an antihole at $800 \mathrm{~cm}^{-1}$ and a hole at $819 \mathrm{~cm}^{-1}$, while irradiation at 2238 yields a hole at $806 \mathrm{~cm}^{-1}$ and antiholes at the other positions. For the $\mathrm{N}^{15}$ compound, however, irradiation at both positions gives holes at $804 \mathrm{~cm}^{-1}$. As previously mentioned, both irradiations yield one antihole near $2360 \mathrm{~cm}^{-1}$ and two holes in the stretching region. The rocking bands behave in a somewhat similar fashion, as irradiation at both $\mathrm{N}-\mathrm{D}$ stretching bands for both $\mathrm{N}^{14}$ and $\mathrm{N}^{15}$ yields one antihole $\left(800 \mathrm{~cm}^{-1}\left(\mathrm{~N}^{14}\right)\right.$ and $\left.797.5 \mathrm{~cm}^{-1}\left(\mathrm{~N}^{15}\right)\right)$.

To make certain that the band at $815 \mathrm{~cm}^{-1}$ is not due to the presence of some diglycine hydrochloride, we examined a deuterium-doped sample of this compound. As we have noted above, the preparation is straightforward and the solid-state structure well-characterized by X-rays. ${ }^{15}$ Our spectra of the undeuterated compound agrees with that of previous workers. ${ }^{6}$ The deuterium-doped sample did not show a band at $815 \mathrm{~cm}^{-1}$.

In Table 2, we list various infrared bands of the $\mathrm{NH}_{2} \mathrm{D}^{+}$ glycine hydrochloride and our assignments, but do not assign the $815 \mathrm{~cm}^{-1}$ band. We next consider the $950-1120 \mathrm{~cm}^{-1}$ region (Figure 6) and the $1270-1410 \mathrm{~cm}^{-1}$ region (Figure 7). Although bands appear in the difference between the deuterated and the nondeuterated compounds, these differences are small and overlap with large non-deuterium-affected bands. There are more than three or four holes and antiholes (Table 2) in each region. It is difficult to associate these uniquely to the different $\mathrm{N}-\mathrm{D}$ positions, but we assign the bands that show the most pronounced antiholes to the N-D in position 3 (the weak hydrogen bond position) (Tables 1 and 2). It has been suggested a number of times that the $\mathrm{NH}_{3}{ }^{+}$or $\mathrm{ND}_{3}{ }^{+}$rock interacts with a combination of the $\mathrm{C}-\mathrm{N}$ stretch, $\mathrm{C}-\mathrm{C}$ stretch, and $\mathrm{CH}_{2}$ rock. ${ }^{10,7}$ Since the $\mathrm{N}-\mathrm{D}$ contribution to the bands arising from such a mixture of valence motions will change with the orientation of the $\mathrm{NH}_{2} \mathrm{D}^{+}$group, each of these bands will be affected by the hole burning. The bands in the 950-
$1120 \mathrm{~cm}^{-1}$ region, we suggest, are such combinations with a predominant contribution from the $\mathrm{CH}_{2}$ rock or the HND deformation of the $\mathrm{NH}_{2} \mathrm{D}^{+}$. Similarly, the bands in the 1270$1410 \mathrm{~cm}^{-1}$ region are another combination with a predominant contribution from one of the $\mathrm{HNH}$ deformations of the $\mathrm{NH}_{2} \mathrm{D}^{+}$.

\section{Summary}

Hole burning of the $\mathrm{N}-\mathrm{D}$ stretching bands of the $\mathrm{NH}_{2} \mathrm{D}^{+}$in the crystalline samples results in reorienting the amino groups. This changes the spectrum of the amino-group vibrations. The infrared bands associated with the amino group are identified by three methods: H/D isotope shifts, $\mathrm{N}^{14} / \mathrm{N}^{15}$ shifts, and hole burning. The amino vibrations should shift with both isotope substitutions and should form holes or antiholes on irradiating the stretches.

There are more bands that meet these criteria than there are simple valence motions (bands and stretches) of the amino group. Each valence motion can give rise to three bands, one for each orientation of the $\mathrm{NH}_{2} \mathrm{D}^{+}$. If the $\mathrm{N}-\mathrm{D}$ motions mix with the displacements of other atoms in forming the normal modes, a large number of vibrations could show the isotope shifts and could hole-burn. This is the most likely reason for the many bands listed in Table 2. Other possibilities include the appearance of combination bands and the existence of Fermi resonances.

The long irradiation times required to produce detectable holes and antiholes resulted in orientations of $\mathrm{NH}_{2} \mathrm{D}^{+}$close to a steady-state distribution. This is most easily seen by noticing that the results of the long $(12 \mathrm{~h})$ broad-band-light irradiations were close to those with the laser (Figures 1-4). The preferred orientation of the $\mathrm{NH}_{2} \mathrm{D}^{+}$under these circumstances is that with the $\mathrm{N}-\mathrm{D}$ in the position with the highest stretching frequency-the position with the lowest zero-point energy. The many holes and antiholes contain much information we have not yet been able to take advantage of. What is missing are detailed assignments, which might be obtained by very extensive calculations that include the effects of hydrogen bonding.

Acknowledgment. We are pleased to acknowledge the support of the National Science Foundation (CHE 9526754).

\section{References and Notes} 5484 .

(1) Yu, G. S.; Li, H. W.; Strauss, H. L. J. Phys. Chem. B 1997, 101 ,

(2) Li, H.-W.; Strauss, H. L. Manuscript in preparation.

(3) Strauss, H. L. Acc. Chem. Res. 1997, 30, 37.

(4) Yu, G. S.; Li, H. W.; Strauss, H. L. J. Phys. Chem. A 1997, 101, 8009.

(5) Tsuboi, M.; Onishi, T.; Nakagawa, I.; Shimanouchi, T.; Mizushima S. Spectrochim. Acta 1958, 12, 253.

(6) Khanna, R. K.; Horak, M.; Lippincott, E. R. Spectrochim. Acta 1966, 22, 1759 .

(7) Dupuy, B.; Garrigou-Lagrange, C. J. Chim. Phys. 1967, 64, 1509.

(8) Dupuy, B.; Garrigou-Lagrange, C. J. Chim. Phys. 1968, 65, 450.

(9) Tsuboi, M.; Takenishi, T.; Nakamura, A. Spectrochim. Acta 1963, 19,271

(10) Suzuki, S.; Shimanouchi, T.; Tsuboi, M. Spectrochim. Acta 1963, $19,1195$.

(11) Al-Karaghouli, A. R.; Cole, F. E.; Lehmann, M. S.; Miskell, C. F.; Verbist, J. J.; Koetzle, T. F. J. Chem. Phys. 1975, 63, 1360.

(12) Frost, W. S. J. Am. Chem. Soc. 1942, 64, 1286.

(13) Wilson, E. B.; Decius, J.; Cross, P. C. Molecular Vibrations; McGraw-Hill: New York, 1955.

(14) Shimanouchi, T. Tables of Molecular Vibrational Frequencies Consolidated; National Standards Reference Data Series, National Bureau of Standards \#39: Washington, D.C., 1972; Vol. I.

(15) Faamau, J. W.; Tiekink, E. R. Z. Kristallogr. 1993, 204, 277. 